\title{
AN ANALYSIS OF SOME CORRELATES OF STEADY POTENTIALS IN MAMMALIAN CEREBRAL CORTEX
}

\author{
B. Libet, Ph.D. and R. W. Gerard, M.D., Ph.D. \\ Dept. of Physiology, University of California School of Medicine, San Francisco, Calif. and \\ Mental Health Research Institute, University of Michigan, Ann Arbor, Mich. (U.S.A.)
}

(Received for publication: October 16, 1961)

(Resubmitted: January 22, 1962)

Evidence bearing on the existence and significance of steady potentials (SP) in the cerebral cortex has recently been reviewed and discussed by O'Leary and Goldring (1959) and Pinneo (1962). We propose to analyze certain aspects of the problems which relate particularly to work we reported some years ago, which explored some of the possible functional correlates of steady potentials in the mammalian cerebral cortex (Libet and Kahn 1947; see also Gerard 1951) ${ }^{1}$.

Those experimental results which are of particular concern to the present discussion are summarized briefly in each case and the analysis of each point will utilize the presently available literature.

\section{Hyperventilation}

During the course of hyperventilating anesthetized cats (dial or ether) for 1-2 min there appeared a surface positive shift in SP, of cortex with respect to bone, of about $1-4 \mathrm{mV}$. The SP came back towards the control level in a similar time after the end of hyperventilation. A subcortical lead (about $3 \mathrm{~mm}$ deep) showed a similar shift in SP with reference to bone, and little or no shift with respect to the surface cortical lead; shifts in SP of the subcortical lead were, however, somewhat obscured by being superimposed upon a gradually diminishing injury potential.

In order to interpret this effect of hyperventilation it may be contrasted with the re-

1 Additional results to be summarized below were presented orally at the April, 1947 meeting of the American Physiological Society. We wish to acknowledge the assistance of $\mathbf{J}$. B. Kahn $\mathrm{J} r$. in these additional experiments. ported effects of asphyxia (tracheal airway clamped), ischemia (arterial occlusion), and anoxia (low inspired $\mathrm{pO}_{2}$ ). Asphyxia results in a somewhat inconsistent initial positive shift that changes to a larger sustained negative shift after about a minute (Goldring and O'Leary 1951a). The initial surface positive shifts in both hyperventilation and asphyxia do not appear to be the same, however, for in our hyperventilation tests the shift was seen when the surface potential was referred to calvarium bone but it was not seen when referred to a subcortical lead. The latter lead-off arrangement is closer to Goldring and O'Leary's transcortical recording arrangement, i.e., surface referred to ventricle. It would thus appear that in hyperventilation the whole thickness of cortex was undergoing a positive shift in SP with respect to calvarium, rather than that a transcortical gradient was developing, as in asphyxia.

Occlusion of the arterial supply to the brain, like asphyxia, has been found to produce a sustained surface negative shift after a delay of some minutes (Leão 1947; Van Harreveld and Stamm 1953). A subcortical lead, however, became positive for several minutes when the surface was going negative, the subcortical lead subsequently also becoming negative (to bone) like the surface (Leão 1951). These results of arterial occlusion are thus roughly similar to those reported for asphyxia. Anoxia, produced by reducing the $\mathrm{pO}_{2}$ in the inspired air, was also found to give a negative shift, but raising the $\mathrm{pCO}_{2}$ produced a positive shift, whether the surface potential was referred to bone (Marshall et al. 1951) or to the blood in the jugular vein (Tschirgi and Taylor 1958). The shifts in SP during asphyxia or arterial occlusion might

Electroenceph. clin. Neurophysiol., 1962, 14: 445-452 

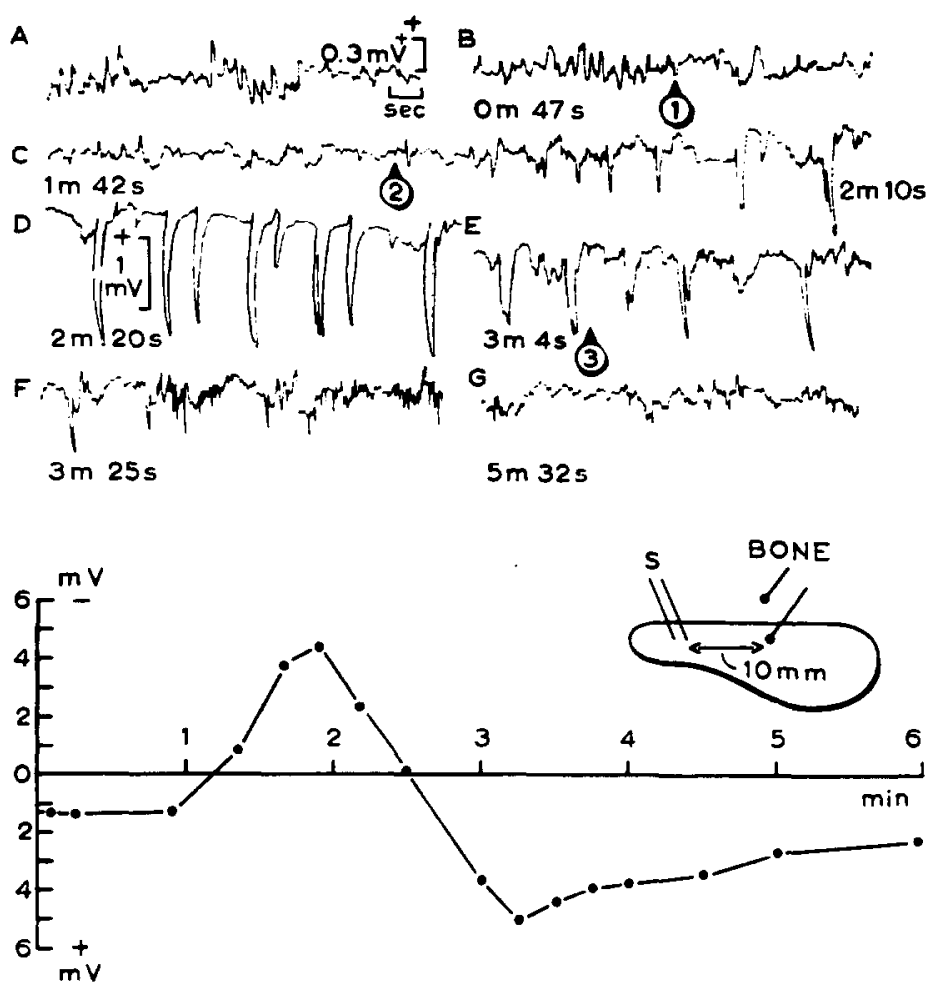

Fig. 1

Spreading depression and epileptiform activity with steady potential. Rabbit, cerebral cortex, dialurethane anesthesia; monopolar leads as shown, recorded simultaneously with r.c. amplified ( $A-$ $G$ ) and d.c.-Victoreen tube electrometer and D'Arsonval galvanometer (graph). Faradic stimulation, $1 \mathrm{sec}$ duration delivered at bipolar $\mathrm{S}$ electrodes, between parts $A$ and $B$. Times after stimulation, for the beginning (or end) of each tracing are given in minutes and seconds below tracings in $B-G$. Arrows (1), (2) and (3) mark the times in the a.c. record that correspond to the beginning of the negative shift, peak negativity and peak positivity respectively in the d.c. record. (A.c. gain setting was the same throughout, but the square wave calibrations on the pen-writing oscillograph used at the time were not linearly proportional to voltage; therefore, calibrations at two voltage levels are given.) Note that polarity on a.c. tracing is positive up (i.e., for cortical surface electrode), but d.c. was plotted negative up so that it would be in accord with d.c. tracings already published by Leão (1947), and others.

thus be due to a combination of the effects of raised $\mathrm{pCO}_{2}$ and lowered $\mathrm{pO}_{2}$ in the brain, with the $\mathrm{CO}_{2}$ effect perhaps predominating more or less in the first few minutes so as to produce the somewhat inconsistent surface positive shift, and the anoxia effect predominating thereafter for some minutes. Neither of these effects, however, would appear to explain the positive shift seen here during hyperventilation.

\section{Spreading depression, SP shift and epileptiform waves}

A slow initially negative, then positive, shift in SP during spreading depression was found by Leão (1947) and independently by us. Also the occurrence of the epileptiform type of large waves, which frequently accompany a spreading depression, was consistently related to a certain phase of this shift in SP. As may be seen in Fig. 1, the epileptiform potentials began only after the negative SP shift had reversed itself (arrow 2, Fig. 1), i.e., when it was proceeding in the direction of surface positivity. The epileptiform waves then built up in size and continued to occur throughout the SP shift in the positive direction. The waves finally diminished rapidly after the final reversal of the SP shift (arrow 3 , Fig. 1) from a point of maximal positivity 


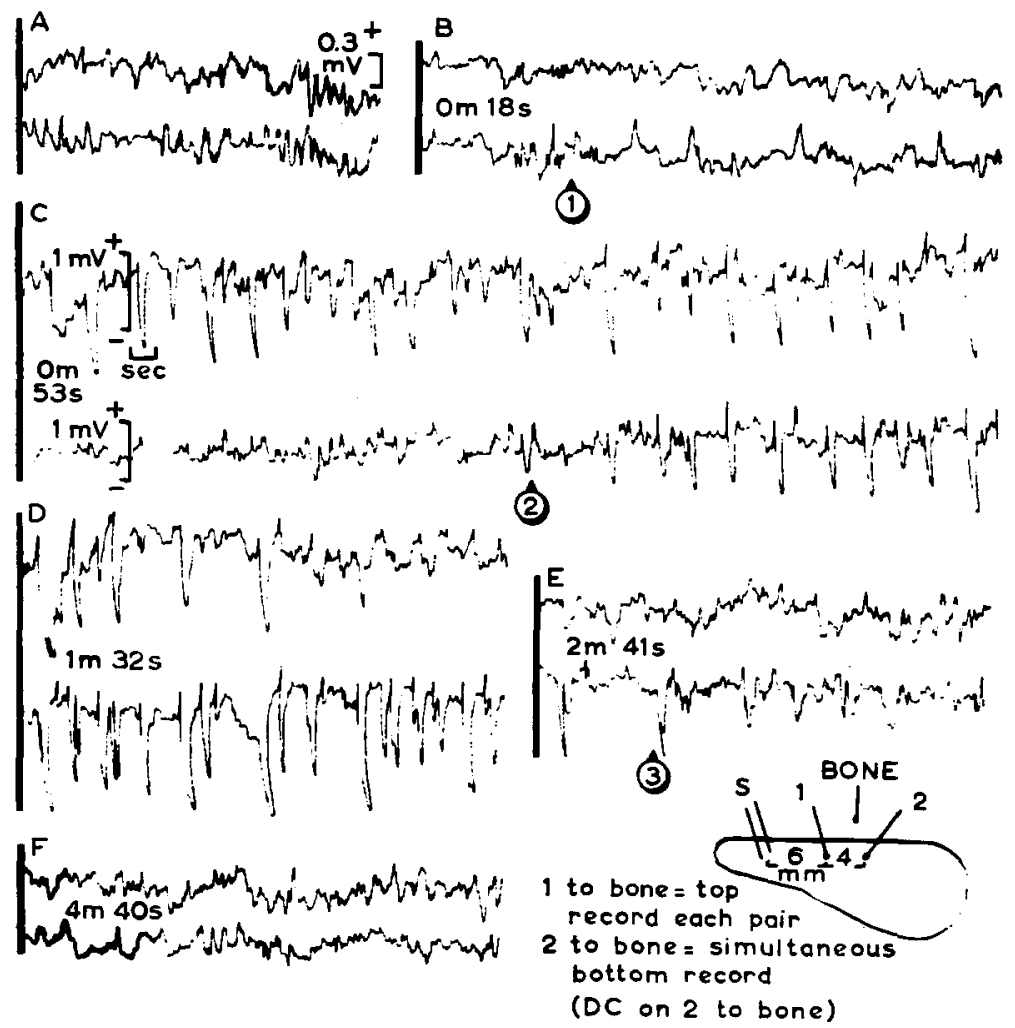

Fig. 2

Spreading depression and epileptiform activity at two points. Conditions as in Fig. 1, but with two monopolar a.c. recordings, electrode 1 to bone in top tracing, electrode 2 to bone in bottom tracing, of each set. D.c. measurements were made only between electrode 2 and bone, and are not shown. Arrows (1), (2) and (3) correspond to beginning of negative shift, peak negativity, and peak positivity respectively in the d.c. record as in Fig. 1. Faint tracing at start of $F$ was retouched.

back towards normal level (see also Fig. 2).

Several additional points of interest should be noted in connection with the appearance of the epileptiform waves: (a) They were predominantly surface-negative in polarity, though they occurred in association with an SP swinging in the direction of positivity. (b) Even though they had already been occurring at some points on the cortex (electrode 1, Fig. 2), they appeared at any given recording electrode only when the SP shift had made its first reversal and was moving in the direction of positivity at that point (at electrode 2, Fig. 2). (c) When they were present at two points on the cortex, they tended to be coupled (Fig. 2). The degree of synchrony between the two, however, can only be crudely estimated with the slow speeds of the pen-writer employed in this work.

\section{Polarity of epileptiform potentials}

The question of the relationship $(a)$ between polarity (and amplitude) of epileptiform potentials and the SP level and polarity should apparently be separated from $(b)$ that between incidence of epileptiform potentials and the intrinsic SP level and polarity. The directions of $(a)$ and $(b)$ are not consistently correlated (see for example, O'Leary and Goldring 1959). Relationship $(b)$ will be discussed separately, below.

An inverse relationship between the polarity (and amplitude) of the predominant surface potentials and the SP polarity (and amplitude)

Electroenceph. clin. Neurophysiol., 1962, 14: 445-452 
has often been observed, for epileptiform as well as for certain other types of cortical waves. The relationship holds up better if the direction of the shift in SP is also considered, not merely the absolute level and polarity of SP. Thus, an SP shift in the surface positive direction, whether intrinsic or brought about by applied direct current, is often associated with predominantly surface negative potentials which tend to be larger, the greater the positive going shift in SP (e.g., see Fig. 1 and 2), when conditions are otherwise suitable for the incidence of such potentials; SP shift in the surface negative direction tends to be associated with the opposite effects on polarity and amplitude (e.g., Libet and Gerard 1941; Bishop and O'Leary 1950). A more recent clear example of this, in relation to the direct cortical response to repetitive electrical stimulation, has been shown by Caspers (1959), even in the reversing effect of $\gamma$-aminobutyric acid on the polarity of the direct cortical response.

There are reports, however, indicating the existence of numerous exceptions to this inverse polarity rule. One such is that of Von Euler et al. (1958) on the hippocampal after-discharge seizures. Vastola (1955) has found that the SP shift across a cell layer of the lateral geniculate, in response to afferent optic nerve volleys, has the same polarity and magnitude as the postsynaptic component of the evoked potentials there, although it is interesting to note that applied polarizing currents still affected the polarity of this evoked potential in the inverse manner (Bishop and O'Leary 1950).

\section{Incidence of epileptiform potentials}

Relationship between the incidence of epileptiform potentials, (or, more generally, between the degree of "spontaneous" neuronal activities of all types - resting EEG waves, epileptiform waves, unit spike discharges) and the level or the direction of shift of SP, however, presents an even less consistent picture. This point has been developed by Fromm et al. (1962), though instances of this inconsistency in the relationship had been noted earlier (e.g., O'Leary and Goldring 1959). In our experiments we saw further examples of this. The epileptiform waves that appeared during a spreading depression arose during the SP shift in the positive direction, although they began when the SP level was still surface negative. (It may be noted that the cell body regions in the deeper cortical layers are going negative during this surface-positive shift, according to Leão, 1951.) On the other hand, strychnine spikes, which after an initial paroxysm disappeared during the negative SP shift produced by similar faradic stimulation of strychninized cortex, remained absent during the succeeding positive SP shift as well. Goldring and O'Leary (1951b) found that "spontaneous" paroxysms of spikes however, after strychnine or several other causes, were associated with a large positive shift in SP. Von Euler et al. (1958) have shown, with microelectrode recordings in the hippocampus, that after-discharge seizures are associated with an SP shift of several millivolts, but with the dendritic layer negative to the axonal side of the neurones during the seizure.

An initial burst of single unit discharge has been reported by Grafstein (1956) preceding the inactive period during an ordinary spreading depression. This initial hyperactivity may be related to the initial paroxysm of spikes which we have observed in strychninized cortex during the first several seconds only of the negative SP shift, immediately following the brief faradic stimulation used to initiate a spreading depression.

The inconsistency between degree or incidence of activity and the SP level appears largely to vanish, however, when one considers only the effect of externally applied, "polarizing", direct currents. Here there is wide agreement that surface positive polarization (i.e., at dendritic end) produces an increase in neuronal activities (resting EEG, epileptiform waves, unit spike discharge in cortex), while surface-negative polarization decreases it (e.g., Libet and Gerard 1941; Bishop and O'Leary 1950; Brookhart and Blachly 1953; Caspers 1959; O'Leary and Goldring 1959; Fromm et al. 1962; Pinneo 1962). An important exception to this rule appears to be the stretch receptor cell of the crayfish, in which making the dendritic end anodal to the axonal side depresses, instead of en-

Electroenceph. clin. Neurophysiol., 1962, 14: 445-452 
hancing, the firing rate (Terzuolo and Bullock 1956); it may be that the polarity relationship for some neuronal properties is different in the invertebrates.

If the inconsistency of relationship between activity and SP is mainly found when intrinsically measured SP is considered, but not with applied or imposed SP, one can suggest a number of reasons why this would be so (assuming that there is an important and basically consistent relationship present). (a) The meaning of the measured intrinsic SP values may be confused by the arrangement of lead-off electrodes; the commonly used surface to indifferent leads may not accurately reflect the level of the transcortical potential difference in different conditions (Bishop and O'Leary 1950; Marshall 1959; Goldring and O'Leary 1951b), or the intracortical distribution of sources and sinks. One example of this kind of difficulty is seen in the similar changes in SP of the surface and subcortical leads during hyperventilation. Another example may be seen in Leão's work (1951) when comparing an intracortical or a nearly subcortical with a surface recording of the shift in SP during spreading depression. (b) The measured intrinsic SP may reflect the summed effects of a number of variables, only some of which may bear a significant relationship to incidence of activity. For example, if diffusion potentials across the blood-brain-barrier contribute to the measured SP in certain conditions (Tschirgi and Taylor 1958), this contribution might obscure other contributions to the measured SP which are more significant indices of neuronal excitation status. (c) The degrees of neuronal activities of various kinds are undoubtedly controlled by a number of factors, many of which are not reflected in a uniform change (if any) in the measured intrinsic SP. Sloan and Jasper (1950) have indeed suggested that there are probably differing types of seizure activities, according to their mode of initiation and transmission.

Thus, it may be suggested that, for a given set of conditions, a change in SP only, as produced by applied direct current, does produce a qualitatively consistent change in neuronal activity; but that the measured intrinsic SP, since it is observed in variously different sets of conditions, cannot by itself be expected to give a uniform index of this relationship. To the extent that SP may influence the degree of activity, how it does so is still open to speculation. For example, the available evidence still does not permit a decision on whether a polarization gradient along the dendrite-axonal axis ("somatic potential" of Gerard and Libet 1940; Libet and Gerard 1941, - the significance of which may be in the gradient itself or simply in the level of membrane polarization and local state of excitation at the dendrite, soma or axon hillock), or whether the relative state of activity of inhibitory vs. excitatory units at different cortical depths, or some other factor, is the important variable being affected in relation to SP. In any case, however, a completely satisfactory theory of the initiation of epileptiform activity must obviously await further work, especially microelectrode analyses of the type employed by Von Fuler $e t$ al. (1958) for the hippocampus.

\section{Coupling or synchronization of epileptiform waves}

The relatively synchronous appcarance of the epileptiform waves at the different points on the cortex which have become involved in a spreading depression had also been noted by Leão (1944). The actual time interval between the incidence of waves at two such points could be quite appreciable and still go undetected at the slow recording speeds used. But, regardless of the quantity of such an interval, the fact remains that the waves at different points are coupled. Yet epileptiform waves may be absent at a point only a few mm away from one which is exhibiting them, and they appear only after the SP at the inactive point has begun to shift in the positive direction (see Fig. 2). These waves may even appear in points separated by cortex that shows only depression without epileptiform waves (Leão 1944), and they may be acutely developed in a pure spreading depression by the local application of acetylcholine or pilocarpine (Van Harreveld and Stamm 1953). These facts indicate that the process which initiates, or permits invasion by, epileptiform waves requires suitable local conditions at each cortical point

Electroenceph. clin. Neurophysiol., 1962, 14: 445--452 
(see also Leão 1944; Morrell 1961) and is independent of any synchronizing mechanism. Once this local excitatory process has lowered the threshold for initiation of, or invasion by, epileptiform waves, however, the actual timing of each discharge can be controlled by another mechanism.

A synchronizing mechanism in epileptiform patterns would seem to require pacemaker cells to initiate each action and a mechanism for spreading the triggering effect of the action. It has been observed that the site of origin or pacemaker for the epileptiform waves, in a spreading depression, appears to move about within the active area (Leão 1944). Shifting of the pacemaker site was also seen in the case of spreading "caffeine waves" in the frog's cerebrum, and could in fact be controlled by applying appropriate direct currents (Libet and Gerard 1941). The mechanism of spread of influence from a pacemaker to the more distant sites might operate via fiber connections from neurone to neurone, via intercellular electric field currents set up by successively activated cells starting with the pacemaker (Gerard and Libet 1940; Gerard 1941; Sloan and Jasper 1950) or via chemical substances released by the activated cells (Grafstein 1956; Van Harreveld and Schadé 1959; Ochs and Hunt 1960). In the present case of coupling of the epileptiform waves during spreading depression, there is no evidence available to enable one to distinguish clearly between these alternatives, although a chemical mechanism would appear to be too slow to produce coupling intervals in the small fractions of a second acting across distances of some millimeters. There is, however, evidence on the mechanism of the spread of the depression itself (see Marshall 1959).

A phenomenon relevant to the distinction between an initiating excitatory process and a more purely synchronizing mechanism was reported by Rosenblueth et al. (1942). They found that epileptiform discharges initiated in one part of the cerebral cortex did not spread to another portion which had been isolated by transcortical cuts (though apparently not including subcortical undercutting); but if discharges were initiated in both such areas independently, then the continuing bursts in both places oc- curred more or less synchronously. In this case, the local excitatory process could be developed at each point by a spread from adjacent cortex only if the latter was intact, whereas the synchronizing mechanism could operate in spite of isolation by transcortical cuts. (It is, of course possible that, in the absence of transcortical cuts, the spread of the excitatory process itself can be sufficient both to develop and then to set off the full response at each point, as apparently occurs in the spread of the "deep response" of Adrian, 1937. This would obviate the significance of any availahle, more purely synchronizing, mechanism.)

Such an analysis may help to explain the inability of an electrically initiated epileptiform discharge to "cross" a transcortical cut directly (Erickson 1940; additional more recent examples of this are summarized by Morrell, 1961). In the instances of successful "crossing" of caffeine waves in the transected frog cerebrum (Gerard and Libet 1940; Libet and Gerard 1941), the soaking of the whole brain in the caffeine may be presumed to have developed the local excitatory process on both sides of the transection; in this case, only a triggering action would be required by a synchronizing mechanism which could operate accross a transection. Similarly, electrically initiated discharges have been reported to spread ephaptically into a completely isolated cortical slab which already had acquired an epileptic tendency (Morrell et al. 1960; Morrell 1961), but not into isolated slabs that were non-epileptic. The finding (Von Euler et al. 195\%) that dendritic after-discharge could apparently cross a cut in the hippocampus, a structure generally prone to exhibit seizure discharges, would also fit this pattern. It follows from this discussion that tests for the existence and nature of purely synchronizing or spreading mechanisms should be designed to avoid being confused by the absence of local activating of excitatory processes, which could make these mechinisms undetectable. On the other hand, it is of course possible to argue that such synchronizing or triggering mechanisms are only of significance in conditions of abnormally high excitability. There exists evidence, however, indicating that they may also operate in conditions not thought to

Electroenceph. clin. Neurophysiol., 1962, 14: 445-452 
involve any raised excitability (Gerard and Libet 1940).

The questions of the significance of intercellular electrical fields and of dendrite-axonal potential differences ("somatic potential") in influencing neuronal activity take on additional and renewed meaning from the observations of Terzuolo and Bullock (1956). Microelectrode recordings in spinal cord neurones and at certain other synaptic regions have shown that there is only a very small effect on the resting transmembrane potential of one cell by activity in other nearby cells, or on the postsynaptic membrane potential by an impulse in the presynaptic terminals (e.g., Eccles 1957). However, the activity-modulating effect of small fields along the axis of the lobster's stretch receptor cell, as described by Terzuolo and Bullock, takes place with similarly apparently inconsequential transmembrane effects of the applied field. The anatomical orientation of masses of neurones in the cerebral cortex and elsewhere would further favor the operation of such field effects.

On the other hand, recent work by Fromm et al. (1962) indicates that the estimated size of the transcortical potential difference produced by an amount of applied direct current that is just able to affect the resting firing pattern of units in the mammalian cortex, may be very large in comparison to the intrinsic SP voltages. While their work is a valuable partial test of the significance of steady potential fields, Fromm et al., however, are aware of a limitation on the interpretation of such results; the actual potential differences developed by the applied current along the axes of appropriate neuronal elements, both excitatory and inhibitory, or the extent to which the local intrinsic patterns of field current are duplicated by the applied current, are not known. Further work on the quantitative aspects of field currents and axial neuronal potential differences in relation to their modulating effects on activity in the cerebral cortex and other CNS sites, would seem to be indicated.

\section{SUMMARY}

An analysis of some aspects of steady potential (SP) phenomena, especially in relation to some earlier experiments on SP correlates of hyperventilation and of epileptiform potentials during spreading depression is presented. The findings by others of SP shift with asphyxia, anoxia, cerebral ischemia and excess $\mathrm{CO}_{2}$ do not appear to explain the positive cortical SP shift during brief hyperventilation. While the polarity (and amplitude) and the incidence of epileptiform (and other) potentials show some correlations with intrinsic SP level and polarity across cell layers, such as the cerebral cortex, these correlations are far from consistent in degree or direction in all different conditons or neural tissues. On the other hand, the correlations of these functions with changes in SP that are induced by polarizing currents applied across such cell layers are highly consistent. Reasons are offered for considering this latter relationship to be a more significant index of the role of SP in these functions. In discussing the possible mechanisms that may produce the observed synchronization or coupling of epileptiform potentials at different points on the cortex, it is suggested that the local process which permits or facilitates the development of such potentials should be considered as one that is potentially distinct from more purely synchronizing mechanisms.

\section{REFERENCES}

Adrian, E. D. The spread of activity in the cerebral cortex. J. Physiol. (Lond.), 1937, 88: 127-161.

Bishop, S. H. and O'LEARY, J. L. The effects of polarizing currents on cell potentials and their significance in the interpretation of central nervous system activity. Electroenceph. clin. N'tirophysiol., 1950, 2: 401-416.

Brookhart, J. M. and Blachly, P. N. The influence of DC potential fields on cerebellar unit activity. Proc. XIXth int. Physiol. Congr. Thérien Frères, Montreal, 1953: 236-237.

Caspers, H. Über die Beziehungen zwischen Dendritenpotential und Gleichspannung an der Hirnrinde. Pflüg. Arch. ges. Physiol., 1959. 269: 157181.

ECCLES, J. C. The physiology of nerve cells. The Johns Hopkins Press, Baltimore, 1957, $270 \mathrm{p}$

Erickson, T. C. Spread of the epileptic discharge. Arch. Neurol. Psychiat. (Chicago), 1940, 43: 429452.

Fromm, G. H., Kapp, H. and Creutzfildt, O. D. Influence of cortical d.c. currents on cortical neuronal activity. Exp. Neurol., 1962, in press. 
Gerard, R. W. The interaction of neurones. Ohio J. Sci, 1941, 41: 160-172.

Gerard, R. W. The physiology of pain: Abnormal neuron states in causalgia and related phenomena. Anesthesiology, 1951, 12: 1-13.

Gerard, R. W. and Libet, B. The control of normal and "convulsive" brain potentials. Amer. J. Psychiat., 1940, 96: 1125-1151.

Goldring, S. and O'Leary, J. L. Experimentally derived correlates between ECG and steady cortical potential. J. Neurophysiol., 1951a, 14: 275288.

Goldring, S. and O'Leary, J. L. Summation of certain enduring sequelae of cortical activation in the rabbit. Electroenceph. clin. Neurophysiol., 1951b, 3: 329-340.

Grafstein, B. Mechanism of spreading cortical depression. J. Neurophysiol., 1956, 19: 154-171.

LEÃo, A. A. P. Spreading depression of activity in the cerebral cortex. J. Neurophysiol., 1944, 7: 359-390.

LEÃo, A. A. P. Further observations on the spreading depression of activity in the cerebral cortex. J. Neurophysiol., 1947, 10: 409-414.

LEÃo, A. A. P. The slow voltage variation of cortical spreading depression of activity. Electroenceph. clin. Neurophysiol., 1951, 3: 315-321.

Libet, B. and Gerard, R. W. Steady potential fields and neurone activity. J. Neurophysiol., 1941, 4: 438-455.

Libet, B. and KaHn Jr., J. B. Steady potentials and neurone activity in mammals. Fed. Proc., 1947, 6: 152.

Marshall, W. H. Spreading cortical depression of Leão. Physiol. Rev., 1959, 39: 239-279.

Marshall, W. H., Essig, C. F. and Dubroff, S. J. Relation of temperature of cerebral cortex to spreading depression of Leão. J. Neurophysiol., 1951, 14: 153-166.

Morrell, F. Electrophysiological contributions to the neural basis of learning. Physiol. Rev., 1961, 41: $443-494$.
Morrell, F., Torres, F., Sandler, B., Ross, G. and OsterberG, K. Excitability of the mirror focus. Electroenceph. clin. Neurophysiol., 1960, 12: 241.

Ochs, S. and Hunt, K. Apical dendrites and propagation of spreading depression in cerebral cortex. J. Neurophysiol., 1960, 23: 432-444.

O'Leary, J. L. and Goldring, S. Changes associated with forebrain excitation processes: d.c. potentials of the cerebral cortex. In J. Field, H. W. MAGoUN and V. E. Hall (Editors), Handbook of physiology, Sect. 1. American Physiological Society, Washington, 1959, 1: 315328.

Pinneo, L. B. Direct current poteritials of the central nervous system. C. C. Thomas, Springfield, Ill., in press.

Rosenblueth, A., Bond, D. D. and Cannon, W. B. The control of clonic responses of the cerebral cortex. Amer. J. Physiol., 1942. 137: 681-694.

SlOAN, N. and JASPER, H. H. The identity of spreading depression and "suppression". Electroenceph. clin. Neurophysiol, 1950, 2: 59-78.

Terzuolo, C. A. and Bullock, 1. H. Measurement of imposed voltage gradient adequate to modulate neuronal firing. Proc. nat. A ad. Sci. (Wash.), 1956, 42: 687-694.

TsChirgi, R. D. and TAYlor, J. 1. Slowly changing bioelectric potentials associated with the bloodbrain barrier. Amer. J. Physiol 1958, 195: 7-22.

Van Harreveld, A. and Schadé, J. P. Chloride movements in cerebral cortex after circulatory arrest and during spreading depression. J. cell. comp. Physiol., 1959, 54: 65-84.

Van Harreveld, A. and Stamm, J. S. Spreading cortical convulsions and depression. J. Neurophysiol., 1953, 16: 352-366.

Vastola, E. F. Steady potential responses in the lateral geniculate body. Electrcinceph. clin. Neurophysiol., 1955, 7: 557-567.

Von Euler, C. V., Green, J. D. and Ricci, G. The role of hippocampal dendrites in evoked responses and after-discharge. Acta phyiol. scand., 1958, 42: 87-111.

Reference: LiBET, B. and GERARD, R. W. An analysis of some correlates of steady potentials in mammalian cerebral cortex. Electroenceph. clin. Neurophysiol., 1962, 14: 445-452. 